suspect that the pruritogenic factors may be prostaglandins (known potentiators of itch) acting with serotonin also released from platelets.

True aquagenic pruritus differs from the itching of polycythaemia in that the teinperature of the water does not seem to be important. It is associated both with the local release of acetylcholine in the skin and with degranulation of the mast cells and raised serum concentrations of histamine? (p 2008). It invites comparison with the relatively common cholinergic urticaria, in which large numbers of tiny itchy weals are provoked by sweating, whether induced by heat exercise or emotion, rather than by contact with water, and for which hydroxyzine is often an effective treatment. True aquagenic urticaria also exists ${ }^{6}$ but is much less common. Aquagenic pruritus, aquagenic urticaria, and cholinergic urticaria may well be related phenomena; further studies could quickly stir up the rather stagnant subject of the mechanisms of pruritus.

1 Champion RH. Urticaria. In: Rook A, Wilkinson DS, Ebling FJG, eds. Textbook of dermatology. Vol 1. 3rd ed. Oxford: Blackwell Scientific Publications, 1979:971-9.

${ }^{2}$ Björnberg A, Löwhagen GB, Tengberg JE. Skin reactivity in workers with and without itching from occupational exposure to glass fibres. Acta Derm Venereol (Stockh) 1979;59:49-53.

${ }^{3}$ Fjellner B, Hägermark O. Pruritus in polycythemia vera: treatment with aspirin and possibility of platelet involvement. Acta Derm Venereol (Stockh) 1979;59:505-12.

${ }^{4}$ Gilbert HS, Warner RRP, Wasserman LR. A study of histamine in myeloproliferative disease. Blood 1966;28:795-806.

5 Smith JB, Willis AL. Aspirin selectively inhibits prostaglandin production in human platelets. Nature; New Biology 1971 ;231:235-7.

${ }^{6}$ Shelley WB, Rawnsley HM. Aquagenic urticaria: contact sensitivity reaction to water. $\mathcal{F} A M A 1964 ; \mathbf{1 8 9}: 895-8$.

\section{Overseas doctors: a step forward into chaos?}

Too many of the overseas doctors who have come to Britain over the last 30 years looking for postgraduate training have been exploited rather than trained. ${ }^{12}$ Now, however, the General Medical Council has announced reforms (13 June, p 1992) that will begin to ensure a fairer deal to those who come in the future and ultimately reduce the numbers of overseas doctors training in Britain. Since, however, the council's concern is with standards and not manpower the changes are likely to produce considerable confusion on the way to these objectives. Overseas doctors certainly need fairer treatment based on some link between the numbers allowed into Britain and the number of training jobs available. Yet the GMC does not know how many overseas doctors will receive limited registration with the new plans, nor does it know how many posts are likely to be approved as suitable for their training.

The GMC has recommended three main changes in the rules governing limited registration. Firstly, it wants to extend sponsorship schemes. About one-third of overseas doctors who come to Britain are sponsored by bodies such as the British Council or the World Health Organisation. ${ }^{3}$ These doctors come well informed, receive good training, and go home with useful experience. It is the unsponsored two- thirds, knowing little about the system, who drift to unsuitable jobs in the periphery and become so bitterly disappointed. So by encouraging sponsorship schemes the GMC will help overseas doctors.

The second part of the plan is to make sure that more overseas doctors prove their quality by passing the Professional and Linguistic Assessment Board examination. This will be less popular with both overseas doctors and sponsoring organisations. Most unsponsored doctors have to take the examination now, but the new changes will mean that more sponsored doctors-most of whom are exempt at the moment -will have to take the examination. As most sponsored doctors are selected and of a high standard they should have little trouble passing, and this change presents only organisational problems. But, with a long waiting list and ever more overseas doctors waiting to take the examination, these organisational problems may be serious, and the GMC should act to reduce them. Furthermore, the council should surely try to make it possible for overseas doctors to take the examination closer to their homes.

The third change made by the council is that from January 1983 overseas doctors with limited registration will be allowed to work only in posts approved for training by the royal colleges and faculties. This is the most important of the changes proposed, and yet it is the one that seems to have been the least thought out. The plan will mean that all hospital posts will either be approved by the royal colleges as suitable for specialist training - and so for doctors with limited registration-or not be approved. Thus all hospital junior jobs will be divided into two tiers.

The GMC appears uncertain about how many posts among those not currently approved by the royal colleges and faculties for their own training are likely to be approved under the new scheme. The recent trend of manpower planning has been to reduce the number of junior posts and increase those of consultants so that no new posts are likely to be created. Instead, large numbers of overseas doctors with limited registration will be competing with growing numbers of home graduates for fewer posts. Meanwhile, hundreds of existing posts may remain unapproved, partly because of lack of resources to upgrade them and partly because the royal colleges will want to keep their manpower projections on course. Who but the desperate (of whom admittedly there may be more) will be available to fill these second-class, nontraining, subconsultant vacancies? And is not, as several speakers during the GMC's debate on the proposals warned, the timetable for introducing an innovation that will require close co-operation between colleges and cash-limited health authorities decidedly optimistic?

What is needed to solve the problem of training overseas doctors is much more comprehensive planning. Immigration quotas, training standards, and service and manpower needs all need to be considered by a single body with adequate data and advice to hand. By acting as if there were no manpower problem the GMC may make a bad problem only worse.

${ }^{1}$ Smith DJ. Overseas doctors in the National Health Service. London: Heinemann for the Policy Studies Institute, 1980.

2 Smith R. Overseas doctors: working, training, and failing in Britain. Br Med f 1981 ;282:1133-4.

${ }^{3}$ Smith R. Overseas doctors: coming to Britain. $\mathrm{Br}$ Med $\mathcal{f} 1981 ; 282$. 1045-7. 